Article

\title{
Optimizing Water Droplet Diameter of Spray Cooling for Dairy Cow in Summer Based on Enthalpy Difference Theory
}

\author{
Tao Ding ${ }^{1, *}$, Baoxi Sun ${ }^{1,2}$, Zhengxiang Shi ${ }^{1,3}$ and Baoming $\mathrm{Li}^{1,3}$ \\ 1 College of Water Resources and Civil Engineering, China Agricultural University, Beijing 100083, China; \\ sunbaoxi@cau.edu.cn (B.S.); shizhx@cau.edu.cn (Z.S.); libm@cau.edu.cn (B.L.) \\ 2 Beijing Engineering Research Center of Safety and Energy Saving Technology for Water Supply Network \\ System, Beijing 100083, China \\ 3 Key Laboratory of Agricultural Engineering in Agricultural Structure and Environment, Ministry of \\ Agriculture and Rural Affairs, Beijing 100083, China \\ * Correspondence: dingtao@cau.edu.cn
}

Received: 6 July 2019; Accepted: 19 September 2019; Published: 24 September 2019

\begin{abstract}
Spray cooling is widely used in relieving heat stress in dairy cows during summer, in which the cooling effect is highly correlated to the diameter of water droplet. To optimize the average diameter of spraying droplet (ADSD) in the process of heat transfer, a theoretical analysis was performed based on the enthalpy difference theory in this study. A platform was built to simulate the processes of spray cooling and its heat stress alleviation to dairy cows in field, and a field experiment was applied to verify the diameter of water droplets suitable for spray cooling. Heat exchange was calculated for eighteen different ADSD in three different environment conditions in the laboratory. The spraying droplets with eighteen diameters were formed by using six different nozzles under the combinations of three pressures and two wind speeds conditions, which were controlled by heaters. The relationship between the ADSD and heat exchange was established with the purpose to determine the appropriate diameter for practical production. In the field test, body temperature, rectal temperature, and respiratory rate of dairy cows were monitored, and the heat exchange was analyzed to verify the optimal diameter spraying cooling in summer. Results showed that the heat exchange generally increased as ADSD increased, and maximum heat exchanges were reached when the ADSD was averaged at $0.914 \mathrm{~mm}$ and $0.995 \mathrm{~mm}$, under which the models of the corresponding nozzles were 9080 and 9010, respectively. After that, the heat exchange decreased as the ADSD continued to increase. Field experiment indicated that the best cooling effect could be achieved with the ADSD of $0.947 \mathrm{~mm}$, and the water consumption for spray cooling was reduced by $22.8 \%$ under the scenario.
\end{abstract}

Keywords: diameter of spray droplet; enthalpy difference theory; heat and mass transfer; water consumption

\section{Introduction}

With the increase demand of dairy milk, healthy and efficient farming of cows is getting more and more attention from both the producers and consumers. High temperature and humid climate in summer is the main cause of heat stress in dairy cows, which may result in a decrease in feed intake, increase of incidence rate, and consequently reduction of milk yield. Heat stress in summer significantly affects the production efficiency of dairy cows [1,2], presenting one of the biggest environmental challenges for the dairy industry worldwide. Thus, cooling dairy cows is therefore essential during hot summer in any confined area. Among a variety of methods, the combination of water spraying in the 
form of small droplets and ventilation can significantly reduce the body temperature and effectively alleviate heat stress of the cows [3-7].

Dozens of studies have been conducted on spray cooling for dairy cows in summer. Focus on the nozzle selection and combination, and water droplet characteristics of the system has been explored [8-11]. More research endeavors have been carried out on evaluating the cooling effect of spraying, determining proper spraying time and interval [12], and assessing the impact of spraying and ventilation combination on the rectal temperature and respiratory rate of the cows [13]. Moreover, the effect of spray cooling on milk yield and cows' health is always mostly concerned [14].

Heat exchange is directly related to the cooling effect of the spraying system. To quantify the heat exchange rate, Gebremedhin and $\mathrm{Wu}[15,16]$ established a heat transfer model and analyzed the process of heat transfer in terms of convection and evaporation of the wet skin surface and fur layer. Then, heat transfer under different conditions of varied wind speed, air temperature, relative humidity, and surface specific humidity was further evaluated through an iteration. To solve the problem of iteration complexity of the method that Gebremedhin and $\mathrm{Wu}[15,16]$ proposed, Khan [17] predicted body temperatures of the cows using multiple linear regression equations and calculated its heat exchange under different environmental combinations. The results were comparative to those reported in the literature with an $8.9 \%$ error. Although the error was acceptable in heat transfer prediction, it was only related to the wind speed and the correlation was only approximately numerical. Some other specific factors affecting the heat transfer were not considered. Additionally, Khan [17] did not study the relationship between the average diameter of the spraying droplet (ADSD) and heat exchange, which is considered crucial for cooling effect, water consumption, and the wastewater generated from spraying in practical application.

The objectives of the paper were to (1) theoretically determine the heat exchange under different ADSD by means of the enthalpy difference theory; (2) optimize the best range of ADSD based on heat exchange calculation and field experiment; and (3) provide a guidance for field application of spraying system for dairy cows in summer.

\section{Methodology}

\section{Theory of Enthalpy Differences and Heat Exchange Calculation Methods}

Heat and mass transfer occurs between the water film formed on the body surface and the air above when water is sprayed on a cow. In such a process, both sensible and latent heat exchanges play important roles in cooling the cows. Due to the temperature difference between the water film and the air, sensible heat exchange happens as a result of heat conduction, convection, and radiation. Whereas the latent heat exchange is the result of water vaporing in the air evaporating. The total heat exchange is an algebraic sum of sensible heat exchange and latent heat exchange.

When the air directly contacts with water film, it forms a saturated air boundary layer, of which the temperature is equal to the water temperature in a place close to the water film. The temperature determines the water vapor concentration or vapor pressure in the boundary layer. When the temperature of the saturated air boundary layer is higher than that of the main air boundary layer, heat is transferred from the saturated air boundary layer to the main air boundary layer. Meanwhile when the concentration of water vapor in the boundary layer is higher than that of the main body, the water vapor is transferred from the boundary layer to the main air. The reduced water vapor in the saturated air boundary layer is supplied by water film during the process of evaporation. In short, the differences of air temperature and water vapor concentration constitute the driving force of sensible heat transfer and latent heat transfer, comprising the total process of heat transfer [18].

The sensible heat exchange at unit time between water and air of such a process could be calculated by:

$$
d Q_{\alpha}=\alpha(t-\theta) d F
$$


where $\alpha$ is the convective heat transfer coefficient of air and water, $\mathrm{W} \cdot \mathrm{m}^{-2} \cdot{ }^{\circ} \mathrm{C}^{-1} ; t$ is the temperature in the saturated air boundary layer, ${ }^{\circ} \mathrm{C}$; and $\theta$ is the dry bulb temperature in the ambient air, ${ }^{\circ} \mathrm{C}$; $d F$ is the contact area between the air and water, $\mathrm{m}^{2}$.

The latent heat exchange of unit time between water and air is expressed by:

$$
d Q_{\beta}=\gamma_{w} \beta_{x}\left(x^{\prime \prime}-x\right) d F
$$

where $\gamma_{w}$ is the latent heat of vaporization of water, $\mathrm{J} \cdot \mathrm{kg}^{-1} ; \beta_{x}$ is the dispersion coefficient between air and water per square meter based on the moisture content difference, $\mathrm{kg} \cdot \mathrm{m}^{-2} \cdot \mathrm{s}^{-1} ; x^{\prime \prime}$ is the water vapor content in the saturated air boundary layer, $\mathrm{g} \cdot \mathrm{kg}^{-1} ; x$ is the water vapor content in ambient air, $\mathrm{g} \cdot \mathrm{kg}^{-1}$; and $d F$ is the contact area between the air and water, $\mathrm{m}^{2}$.

The mass transfer coefficient is also known as the wet exchange coefficient and the evaporation coefficient, which can be obtained from the convective mass transfer coefficient:

$$
\beta_{x}=h_{m} \rho
$$

where $h_{m}$ is the convective mass transfer coefficient, $\mathrm{m} \cdot \mathrm{s}^{-1}$; and $\rho$ is the density of the water vapor, $\mathrm{kg} \cdot \mathrm{m}^{-3}$.

The convective mass transfer coefficient can be determined from the Sherwood number:

$$
\begin{gathered}
h_{m}=S h \frac{D}{d} \\
S h=c \operatorname{Re}^{a} S c^{b}
\end{gathered}
$$

where $D$ is the water vapor diffusion coefficient, $\mathrm{m}^{2} \cdot \mathrm{s}^{-1} ; d$ is the diameter of the cow, $\mathrm{m}$; $S h$ is the Sherwood number; Re is the Reynolds number; and $S c$ is the Schmidt number.

The total heat exchange is determined by:

$$
d Q=d Q_{\alpha}+d Q_{\beta}=\left[\alpha(t-\theta)+\gamma_{w} \beta_{x}\left(x^{\prime \prime}-x\right)\right] d F .
$$

According to the relationship between convective heat transfer coefficient and mass transfer coefficient: $\frac{h}{h_{m}}=\rho c_{p} L e^{2 / 3}, 0.6<\operatorname{Pr}<60,0.6<S c<3000, \frac{h}{h_{m} \rho}=\frac{\alpha}{\beta_{x}}=c_{p} L e^{2 / 3}$. Based on the heat and mass transfer processes, the thermal diffusion and mass diffusion are similar, so that the Lewis number is treated as 1 and then the Lewis relationship can be obtained as $\beta_{x}=\alpha / c_{p}$, where $c_{p}$ is specific heat capacity of moist air, $\mathrm{kJ} \cdot \mathrm{kg}^{-1} \cdot \mathrm{K}^{-1}$. Putting these into the formula, then:

$$
d Q=\beta_{x}\left[c_{p}(t-\theta)+\gamma_{w}\left(x^{\prime \prime}-x\right)\right] d F
$$

Replacing the latent heat of vaporization of water with the enthalpy of water vapor and replacing the specific heat capacity of moist air with $\left(1.01+1.84 x^{\prime}\right)$ to get:

$$
\begin{aligned}
d Q & =\beta_{x}\left[\left(1.01+1.84 x^{\prime \prime}\right)(t-\theta)+(2500+1.84 \theta)\left(x^{\prime}-x\right)\right] d F \\
& =\beta_{x}\left\{\left[(1.01 t+(2500+1.84 t)) x^{\prime}\right]-[(1.01 \theta+(2500+1.84 \theta)) x]\right\} d F \\
& =\beta_{x}\left(i^{\prime}-i\right) d F
\end{aligned}
$$

where $i^{\prime \prime}$ is enthalpy of moist air in the saturated air boundary layer, $\mathrm{kJ} \cdot \mathrm{kg}^{-1}$; and $i$ is the enthalpy of moist air in the ambient air, $\mathrm{kJ} \cdot \mathrm{kg}^{-1}$. 


\section{Experiment}

\subsection{Laboratory Experiment}

\subsubsection{Experimental Settings}

An experimental platform was built to simulate the different summer environment and spraying conditions in the laboratory for dairy cows (Figure 1). The experiment platform was composed of three parts, namely spraying system, heating system, and environment control system. The spraying system provided spraying simulation of the practice, and it included a water pump, a pressure gauge, a flow meter, a control valve, and a pipeline connecting unit. The heating system provided an inner heat source to simulate the body temperature dairy cows. The environmental control system adjusted the experimental temperature and humidity in order to create high temperature and humidity environmental conditions.

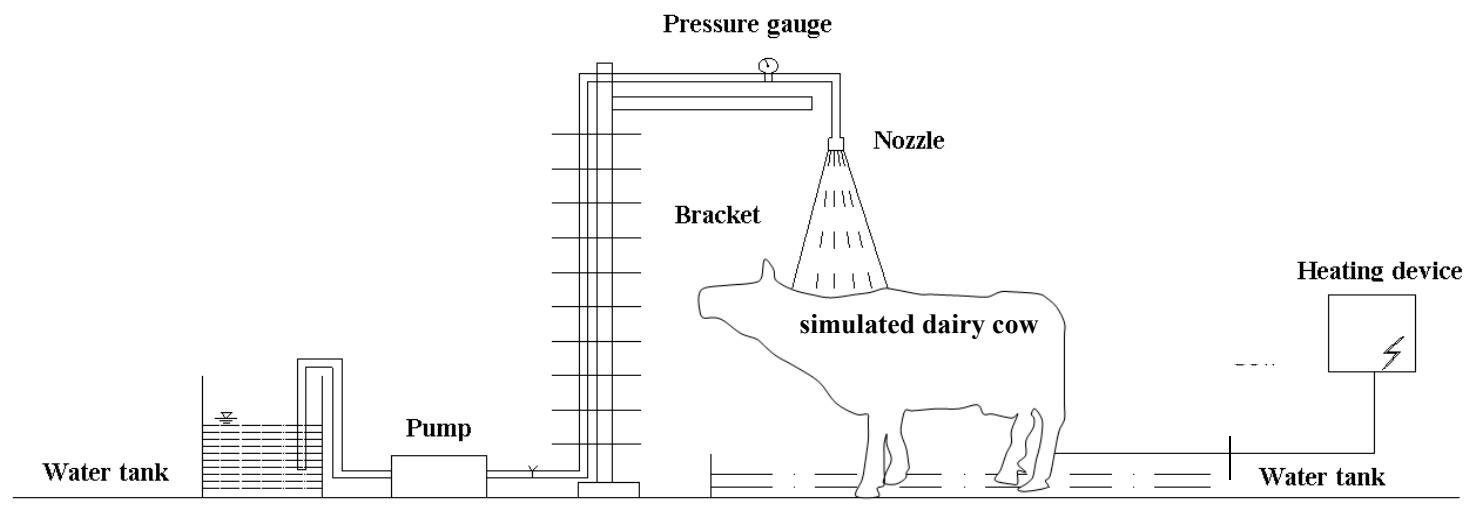

Figure 1. The schematic representation of test bench.

As shown in Figure 1, a simulation dairy cow, which was made in accordance with proportion of 1:1 $(1.4 \mathrm{~m} \times 2 \mathrm{~m})$, was applied in the experimental platform. The simulated dairy cow was made of the steel skeleton structure and a heater was installed inside to reach the normal body temperature of the real dairy cow. The steel skeleton structure was covered with silica gel similar to the dairy cow's body, and the cowhide wool was covered on the surface. The selection of dimension of the simulation dairy cow was based on the Chinese Holstein. A heat sensing system was equipped into the simulated cows.

In the experiments, the temperature of the saturated air boundary layer was monitored using a thermocouple on the surface of the simulated cow. The thermocouple was an AZ88598 4 channel K type with a measurement range from -200 to $1370{ }^{\circ} \mathrm{C}$, and its accuracy was $\pm 0.3^{\circ} \mathrm{C}$. The temperature and humidity of the ambient air boundary layer was monitored with a temperature and humidity sensor (HoBoU14-001), which had a temperature measuring range of -20 to $50{ }^{\circ} \mathrm{C}$ with a resolution of $\pm 0.2{ }^{\circ} \mathrm{C}$ and a humidity range of 0 to $100 \%$ with an accuracy of $2.5 \%$. The monitoring interval time was set at $1 \mathrm{~s}$.

A laser precipitation monitor (LPM) (THIES Company, Germany) was used to measure the ADSD, which was based on the optical principle and laser technology to realize real-time monitoring of water droplet density, diameter, spraying speed, and intensity, as shown in Figure 2. The measurement range of droplet diameter was from 160 to $8000 \mu \mathrm{m}$ and the range of particle velocity was $0.2-20 \mathrm{~m} \cdot \mathrm{s}^{-1}$. Output of the equipment included the distribution of water droplet diameter and the speed, number of water droplets, spraying intensity and precipitation volume. Six standard jet nozzles (with models of 9010,9030, 9060, 9080, 90100, and 90120, AVP, Japan) were tested to generate different droplet diameters. The numbers of model were the combination of spraying angle and its flowrate. For an example of 9080, spray angle of the nozzle was 90 degrees, while its flow rate was $80 \mathrm{~L} \cdot \mathrm{min}^{-1}$. In a total, eighteen ADSDs could be generated by six nozzles under three pressures, which were pre-tested in the 
laboratory prior to the experiments [19] (Figure 2). The performance parameters of the six nozzles are shown in Table 1.
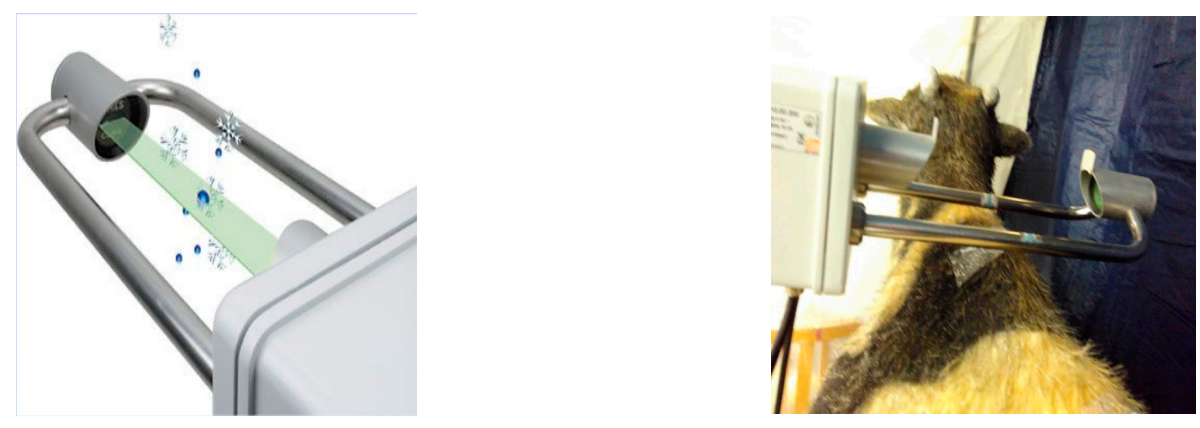

Figure 2. The LPM for measuring the ADSD on the simulated cow neck area.

Table 1. Performance of nozzles.

\begin{tabular}{cccc}
\hline \multirow{2}{*}{ Model of Nozzle } & Pressure & Flow & ADSD \\
\cline { 2 - 4 } & MPa & $\mathbf{m}^{\mathbf{3}} \cdot \mathbf{h}^{\mathbf{- 1}}$ & $\mathbf{m m}$ \\
\hline \multirow{3}{*}{9010} & 0.15 & 0.021 & 0.508 \\
& 0.20 & 0.026 & 0.486 \\
9030 & 0.25 & 0.034 & 0.475 \\
\hline \multirow{3}{*}{9060} & 0.15 & 0.165 & 0.576 \\
& 0.20 & 0.191 & 0.566 \\
& 0.25 & 0.213 & 0.555 \\
\hline \multirow{2}{*}{9080} & 0.15 & 0.250 & 0.801 \\
& 0.20 & 0.292 & 0.778 \\
& 0.25 & 0.327 & 0.760 \\
\hline \multirow{2}{*}{90100} & 0.15 & 0.323 & 0.914 \\
& 0.20 & 0.377 & 0.893 \\
& 0.25 & 0.423 & 0.884 \\
\hline \multirow{2}{*}{90120} & 0.15 & 0.417 & 1.047 \\
& 0.20 & 0.492 & 1.003 \\
& 0.25 & 0.543 & 0.995 \\
\hline & 0.15 & 0.513 & 1.210 \\
& 0.20 & 0.603 & 1.201 \\
& 0.25 & 0.676 & 1.197 \\
\hline
\end{tabular}

\subsubsection{Location of Temperature Measurements}

Typically, the cooling efficiency of the neck of cows is higher, which is considered as an area with good heat dissipation. Thus, measuring points of skin temperatures $\left(t_{1}\right)$ were set on the neck [20], and another point above the skin was selected to monitor the air temperature in the saturated boundary layer $\left(t_{2}\right)$. The air temperature and humidity $\left(t_{3}, \varphi\right)$ of the main stream were monitored by using the temperature and humidity HoBo sensors (Figure 3 ). 

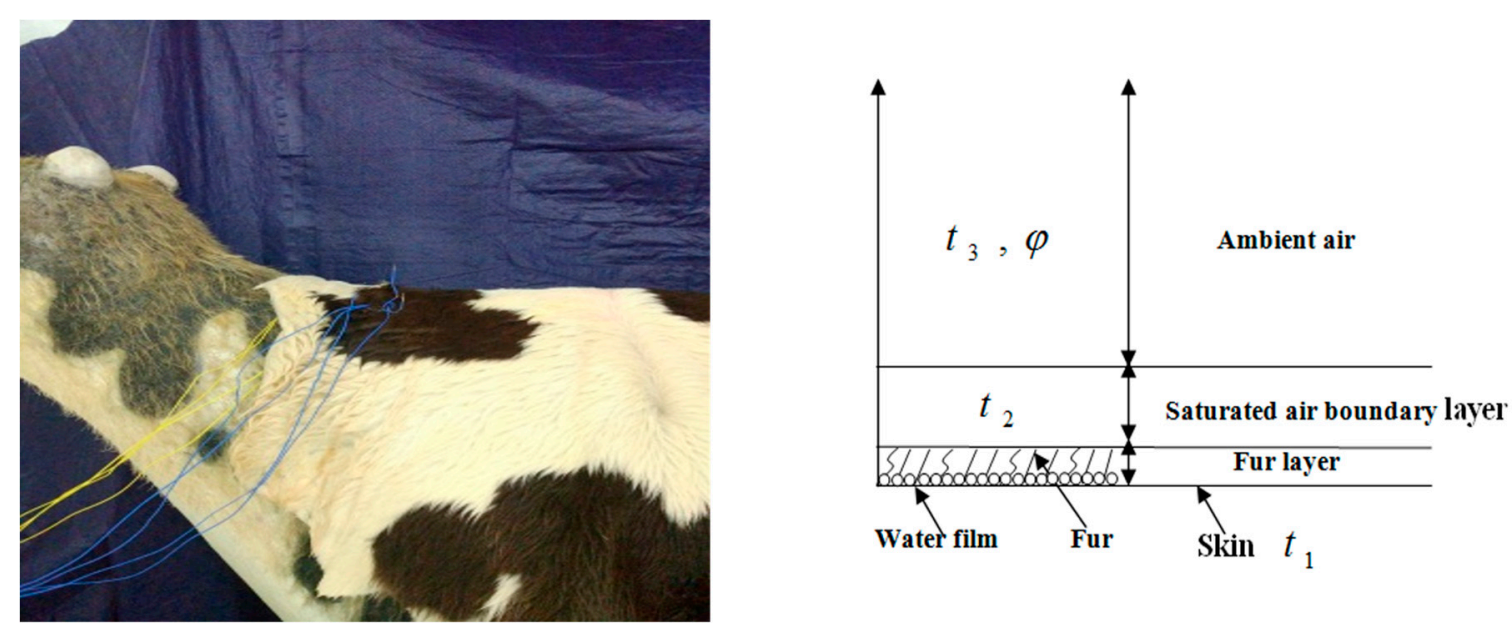

Figure 3. The measurement layout on the simulated cow's neck.

\subsubsection{Experimental Procedure}

The heating device inside the simulated cow was turned on to raise body temperature the cow to $38.5^{\circ} \mathrm{C}$. During the measurement, air temperature and humidity were adjusted to one of three settings of $30{ }^{\circ} \mathrm{C}$ and $60 \%, 33{ }^{\circ} \mathrm{C}$ and $70 \%$, and $35^{\circ} \mathrm{C}$ and $50 \%$ to simulate the hot environment. The duration of each spraying was controlled at $2 \mathrm{~min}$ according to the practical management of a dairy farm in China. After stopping spraying, a mixing fan was operated to ventilate the cow to enhance its cooling effect and wind speed was tested. Body temperature of the cow as well as the temperature and humidity of the saturated air boundary layer and ambient air were recorded within the final $5 \mathrm{~min}$ of spraying. These procedures were repeated with the combinations of six different nozzles (models 9010, 9030, $9060,9080,90100$, and 90120), three spraying pressures $(0.15,0.2$, and $0.25 \mathrm{MPa})$ and two wind speeds $\left(1.92\right.$ and $\left.2.85 \mathrm{~m} \cdot \mathrm{s}^{-1}\right)$. According to the laboratory test results, the appropriate ADSDs were selected with their corresponding nozzles, and they were used in the verification experiment in the field.

\subsubsection{Calculation of Heat Exchange}

The theory of enthalpy differences formula fully covers the sensible heat exchange and latent heat transfer in the heat exchange process. Therefore, the test calculated the heat exchange capacity of the cow's body surface and the surrounding ambient air using the formula. Among them, the enthalpy of the saturated air boundary layer and the ambient air layer can be calculated from the measured temperature and humidity, which were monitored from the neck area of the cow, a sensitive part of spray cooling to relieve heat stress. Therefore, the amount of heat exchange in the neck area was studied in this paper.

\subsection{Field Experiment}

\subsubsection{Surveyed Dairy Housing}

The field experiment was carried out from 1-31 July 2017 at a dairy farm in Beijing, China. The dairy building was an open-sided barn with its ridge oriented in the north-to-south direction. The building, having a symmetrical layout of the west and east parts, was $174 \mathrm{~m}$ in length, which was divided into 29 spans of $6 \mathrm{~m}$. The fans above the headlocks were uniformly spaced $12 \mathrm{~m}$ apart, which were operated from 8:00 to 17:00. The layout of the bam is shown in Figure 4. 

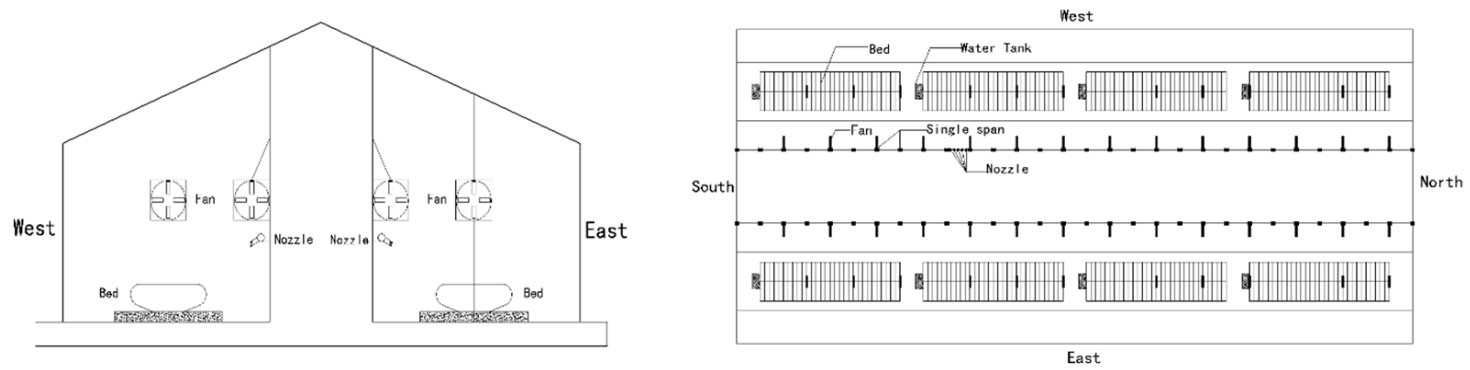

Figure 4. Overhead view and side-view diagrams of the surveyed dairy barn.

\subsubsection{Spraying System}

The right side of the barn was set as the treated area (Figure 5a). Based on the test for optimal ADSD in the laboratory, the nozzles with models of 9080 and 90100 were replaced in the area. The nozzles were located $0.3 \mathrm{~m}$ above the headlocks on the water supply pipe. The distance between adjacent nozzles was $1.2 \mathrm{~m}$ (Figure 5). In the field experiment, the pressure of the spray pipeline was $0.1 \mathrm{Mpa}$, under which the ADSD of the two nozzles was 0.947 and $1.127 \mathrm{~mm}$, respectively. The spraying system was cycled with $2 \mathrm{~min}$ on (water spraying) and $5 \mathrm{~min}$ off (ventilating).

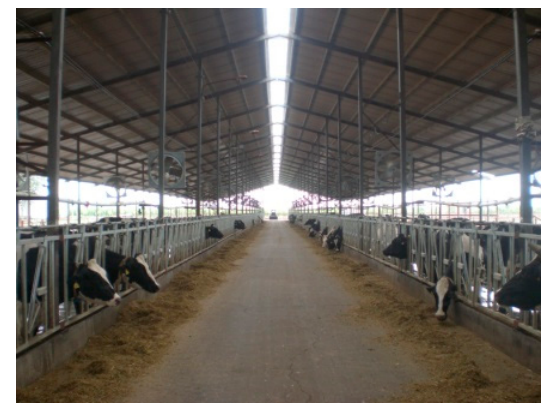

(a)

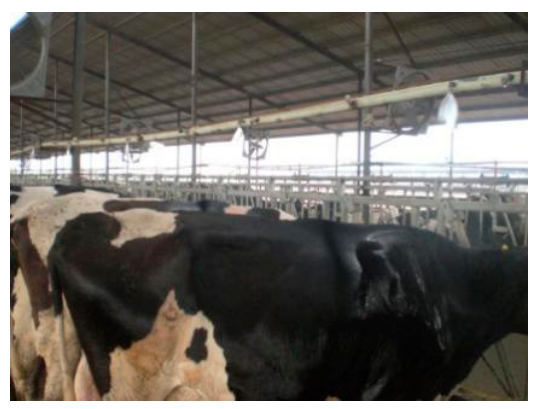

(b)

Figure 5. Photos of the field experiment site.

\subsubsection{Wind Speed Measurements}

The wind speed in the test area was measured by a hot wire anemometer and data were recorded at every $5 \mathrm{~s}$. The average value of 10 measurements was used as the wind speed.

\subsubsection{Physiological Index Measurements}

The measured physiological indexes included body surface temperature, rectal temperature, and respiratory rate of the cows. During the test, each physiological index was measured before spraying and after spraying by three people simultaneously to collect body temperature, rectal temperature, and respiratory frequency of the cow. During the experiment, the cows were locked in a neck yoke, confining them to the spray area in order to prevent the influence of cow movement. After data collection of one cow, the next was randomly selected until a total of 30 cows were measured under the same ADSD. These measurements were repeated with different nozzles. The physiological indexes of the cows were tested under different ADSDs and spraying times. The respiratory rate was manually accounted by the rise and fall of the abdomen with a stopwatch. The surface temperature of the cow was monitored based on the infrared imaging distribution during the process of spraying, which was measured by a thermal imager (Model S6; with a temperature range of -20 to $650{ }^{\circ} \mathrm{C}$, and thermal imager displays to $0.1^{\circ} \mathrm{C}$ with a measurement accuracy of $\pm 2 \%$ ). The rectal temperature was measured with an electronic rectal thermometer (Model K-028 SY; with a precision of $\pm 0.1^{\circ} \mathrm{C}$, from 32 to $42.9^{\circ} \mathrm{C}$ ). 


\subsubsection{Environmental Indicators}

A temperature and humidity recorder (model U14-001) was placed above the headlocks for temperature and humidity data collection in the dairy farming site.

\subsubsection{Calculation of Body Surface Temperature}

Due to the sensitivity to temperature differences in each region of the cow body, the thermograph was divided into two regions, including the neck and the abdomen (as shown in Figure 6). The average of 6 measurement points on the neck was taken as the surface temperature of the neck region; the average of 12 equally-spaced points in the abdominal region was taken as the temperature of the abdomen region. Neck and abdominal measurements were taken simultaneously, four times, and the average for each region was taken as the final temperature.

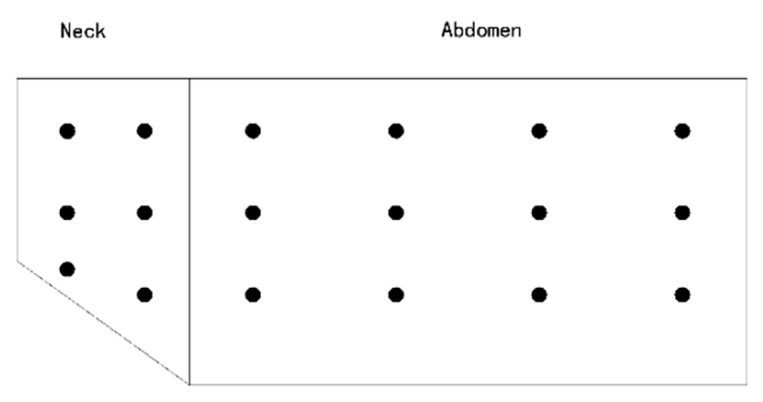

Figure 6. The layout of skin temperature.

\subsubsection{Calculation of Heat Exchange}

The calculation of heat transfer was based on the theory of enthalpy differences formula. The average wind speed at the height of $1.5 \mathrm{~m}$ was $1.52 \mathrm{~m} \cdot \mathrm{s}^{-1}$ under normal fan operation. The equivalent diameter of a cow was estimated as $0.8 \mathrm{~m}$ and the skin area of a cow was $2.1 \mathrm{~m}^{2}$.

\section{Results and Discussion}

\subsection{ADSD Based on Laboratory Experiment}

In the laboratory test, the distribution characteristics of ADSD were analyzed by simulated cow with the equipment of LPM. During the experimental test, the nozzle rated pressure was $0.15,0.2$, $0.25 \mathrm{MPa}$, and the flow rate was measured by a flow meter. The result was shown in Table 1.

According to the above 18 different ADSDs, based on the enthalpy difference theory, the temperature and humidity sensors were used to test the heat exchange capacity between the simulated dairy cow and the three combinations. Figure 7 shows the effects of ADSD on heat exchange under three temperature and relative humidity combinations of $30{ }^{\circ} \mathrm{C}$ and $60 \%$ (combination I), $33^{\circ} \mathrm{C}$ and $70 \%$ (combination II), and $35{ }^{\circ} \mathrm{C}$ and $50 \%$ (combination III).

Under combination I, when the wind speeds were $1.91 \mathrm{~m} \cdot \mathrm{s}^{-1}$ and $2.85 \mathrm{~m} \cdot \mathrm{s}^{-1}$, the heat exchange reached the maximum at $0.995 \mathrm{~mm}$ ADSD, which was $374.1 \mathrm{~W}$ and $466.0 \mathrm{~W}$. Under combination II, when the wind speed was $1.91 \mathrm{~m} \cdot \mathrm{s}^{-1}$, the heat exchange reached the maximum $(378.8 \mathrm{~W})$ at $0.995 \mathrm{~mm}$ ADSD. When the wind speed was $2.85 \mathrm{~m} \cdot \mathrm{s}^{-1}$, the heat exchange reached the maximum $(519.9 \mathrm{~W})$ at $0.914 \mathrm{~mm}$ ADSD. Under combination III, when the wind speeds were $1.91 \mathrm{~m} \cdot \mathrm{s}^{-1}$ and $2.85 \mathrm{~m} \cdot \mathrm{s}^{-1}$, the heat exchange reached the maximum at $0.995 \mathrm{~mm}$ ADSD, which was $842.7 \mathrm{~W}$ and $1350 \mathrm{~W}$, respectively.

From the Figure 7, a trend was observed that with the ADSD increased, the heat transfer rate gradually increased to a maximum and then gradually decreased. The heat transfer peak points were in the ADSD range of $0.914-0.995 \mathrm{~mm}$. When the ADSD was $0.995 \mathrm{~mm}$, the heat exchange reached the maximum value. However, the heat exchange showed a decreasing trend with the increase in ADSD 
when the average droplet diameter exceeded $0.995 \mathrm{~mm}$. According to the laboratory test results, the nozzle size corresponding to the ADSDs were 9080 and 90100.

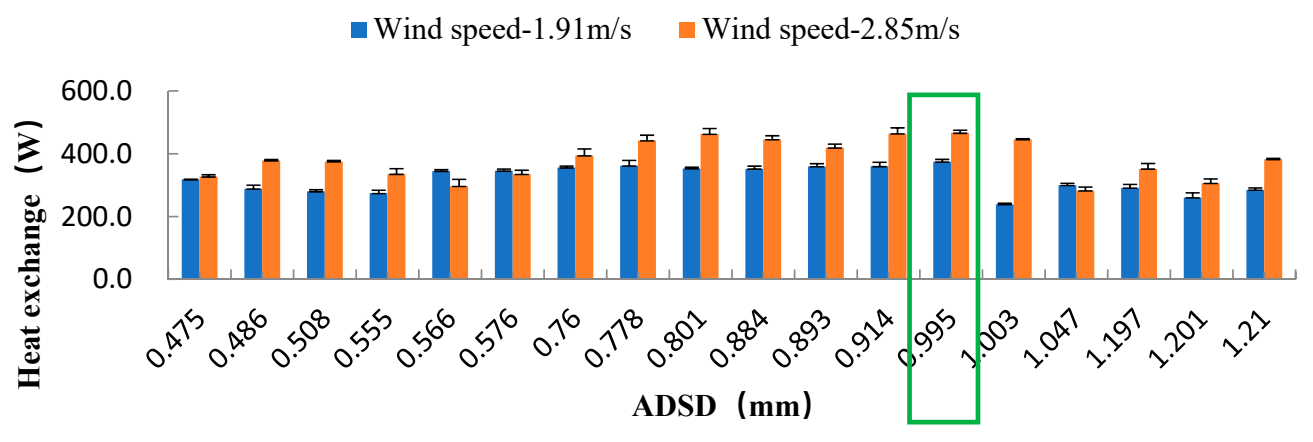

(a)

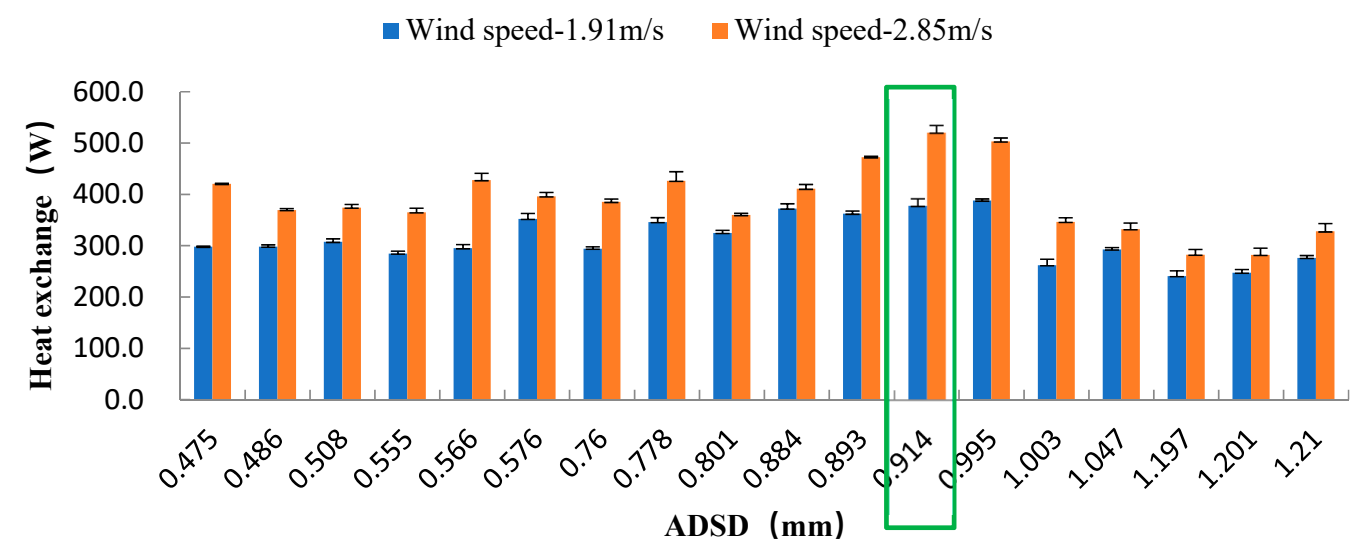

(b)

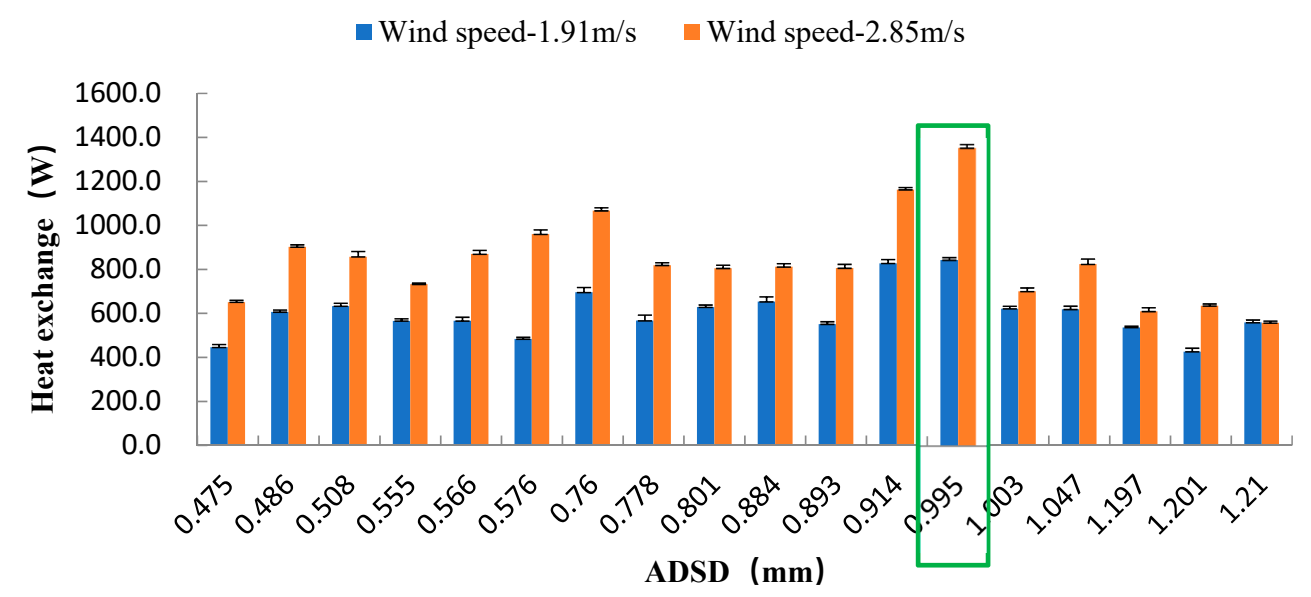

(c)

Figure 7. Heat exchange of different ADSD under three conditions: (a) combination I; (b) combination II; (c) combination III. 


\subsection{Field Experiment Discussion}

\subsubsection{The Body Temperature of the Cows}

The body temperature of dairy cows was collected using the infrared thermal imager (ITI), as shown in Figure 8. The ITI pictures show the body temperatures at two different times (Table 2, the significant difference coefficient $\mathrm{P}<0.01$ ): before spraying and after spraying. The temperature data collection points were selected based on the layout of body surface temperature. Experimental test results were shown that for dairy cow neck and abdomen areas. It was not the larger the particle size of ADSD, the better the cooling effect, and the lower the body surface temperature of the dairy cows.

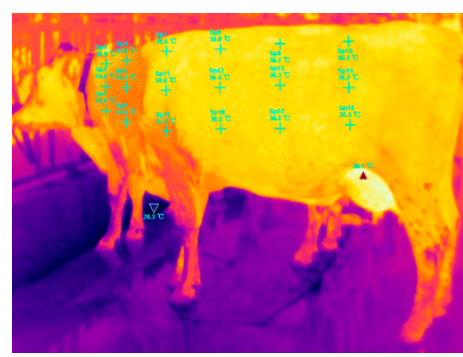

(a)

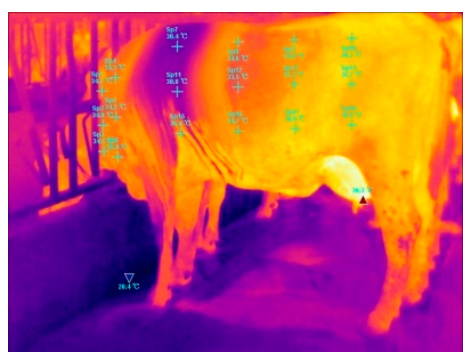

(b)

Figure 8. Photos of skin temperature: (a) before spraying; (b) after spraying.

Table 2. The average skin temperature with three different average spray droplet diameters.

\begin{tabular}{ccccc}
\hline Area & ADSD (mm) & $\begin{array}{c}\text { Before Spraying } \\
\left({ }^{\circ} \mathbf{C}\right)\end{array}$ & $\begin{array}{c}\text { After Spraying } \\
\left({ }^{\circ} \mathbf{C}\right)\end{array}$ & $\begin{array}{c}\text { Temperature } \\
\text { Difference I }\left({ }^{\circ} \mathbf{C}\right)\end{array}$ \\
\hline \multirow{2}{*}{ Neck } & 0.947 & $36.0 \pm 1.0^{\mathrm{A}}$ & $35.0 \pm 1.0^{\mathrm{A}}$ & $1.1 \pm 0.8^{\mathrm{A}}$ \\
& 1.127 & $35.5 \pm 0.7^{\mathrm{A}}$ & $34.6 \pm 0.5^{\mathrm{A}}$ & $0.9 \pm 0.8^{\mathrm{A}}$ \\
\hline \multirow{2}{*}{ Abdomen } & 0.947 & $36.2 \pm 1.0^{\mathrm{A}}$ & $34.9 \pm 0.8^{\mathrm{A}}$ & $1.4 \pm 0.8^{\mathrm{A}}$ \\
& 1.127 & $35.6 \pm 0.9^{\mathrm{A}}$ & $34.0 \pm 0.7^{\mathrm{A}}$ & $1.5 \pm 0.8^{\mathrm{A}}$ \\
\hline
\end{tabular}

\subsubsection{The Rectal Temperature of Cows}

Since cows are warm-blooded animals, their rectal temperature does not fluctuate greatly due to external factors under normal physiological conditions. The change in rectal temperature under spray cooling was limited to small changes. The normal rectal temperature of cows was from 37.5 to $39.5^{\circ} \mathrm{C}$. According to the data in Table 3, the rectal temperature of the cows under different ADSDs was within the normal rectal temperature range at the time before spraying and the time after spraying. (The significant difference coefficient $\mathrm{P}<0.05$, the different letters in the table indicate significant differences at $\mathrm{P}<0.05$ levels at different spray particle sizes.)

Table 3. The average rectal temperature with three different ADSDs.

\begin{tabular}{ccc}
\hline ADSD (mm) & Before Spraying, $\left({ }^{\circ} \mathbf{C}\right)$ & After Spraying, $\left({ }^{\circ} \mathbf{C}\right)$ \\
\hline 0.947 & $38.62 \pm 0.22^{\mathrm{a}}$ & $38.46 \pm 0.54^{\mathrm{a}}$ \\
1.127 & $39.28 \pm 0.17^{\mathrm{b}}$ & $39.20 \pm 0.19^{\mathrm{a}}$ \\
\hline
\end{tabular}

\subsubsection{The Respiratory Rate of Cows}

The changes in respiratory rate of cows under different ADSDs were shown in Table 4. Under the two ADSDs the respiratory rate reduction values at the time of spraying compared to before spraying were 4.2 and 2.1 breaths $\mathrm{min}^{-1}$. (The significant difference coefficient $\mathrm{P}<0.01$, the letter $\mathrm{A}$ in the table indicates that the difference is significant at $\mathrm{P}<0.01$ levels under different spray particle sizes.) 
Compared with the ADSD of $1.127 \mathrm{~mm}$, the ADSD of $0.947 \mathrm{~mm}$ had a better effect on reducing the respiratory rate of cows, and was more suitable for use in dairy cow spray cooling.

Table 4. The average respiration rate with three different averages spray droplet diameters.

\begin{tabular}{cccc}
\hline ADSD (mm) & $\begin{array}{c}\text { Breaths Before } \\
\text { Spraying }\left(\mathbf{m i n}^{-\mathbf{1}}\right)\end{array}$ & $\begin{array}{c}\text { Breaths after Spraying } \\
\left(\mathbf{m i n}^{-1}\right)\end{array}$ & $\begin{array}{c}\text { Breaths Difference I } \\
\left(\mathbf{m i n}^{\mathbf{- 1}}\right)\end{array}$ \\
\hline 0.947 & $77.7 \pm 9.6^{\mathrm{A}}$ & $73.4 \pm 8.8^{\mathrm{A}}$ & $4.2 \pm 5.4^{\mathrm{A}}$ \\
1.127 & $71.4 \pm 6.4^{\mathrm{A}}$ & $69.4 \pm 6.5^{\mathrm{A}}$ & $2.1 \pm 4.9^{\mathrm{A}}$ \\
\hline
\end{tabular}

\subsubsection{The Heat Exchange of Cows}

The changes in heat exchange of cows under different ADSDs were shown in Table 5. In the condition ADSD of $0.947 \mathrm{~mm}$, the decrease of respiratory rate and the increase of heat transfer volume were more obvious than those in the ADSD of $1.127 \mathrm{~mm}$. We found that when the ADSD was larger than $0.947 \mathrm{~mm}$, the cooling effect would not increase, because the larger the ADSD gravity and kinetic energy were, the water droplets would flow along the abdomen resulting in no sufficient water film on the body surface of the cow. This would reduce the heat transfer process. In addition, the larger the ADSD, the greater the amount of sewage generated. Therefore, the choice of nozzle size to alleviate the heat stress of the cow should be considered the ADSD formed under its working pressure. In the experimental conditions of this study, the optimal ADSD at $0.1 \mathrm{MPa}$ working pressure was $0.947 \mathrm{~mm}$. The water consumption in ADSD of $0.947 \mathrm{~mm}$ was 22.86\% lower than that of ADSD of $1.127 \mathrm{~mm}$.

Table 5. The average heat exchange with three different average spray droplet diameters $(\mathrm{P}<0.05)$.

\begin{tabular}{ccccccc}
\hline $\begin{array}{c}\text { ADSD } \\
(\mathbf{m m})\end{array}$ & $\begin{array}{c}\text { Temperature in } \\
\text { Saturated } \\
\text { Boundary Layer } \\
\left({ }^{\circ} \mathbf{C}\right)\end{array}$ & $\begin{array}{c}\text { Temperature in } \\
\text { Ambient Air } \\
\left({ }^{\circ} \mathbf{C}\right)\end{array}$ & $\begin{array}{c}\text { Humidity in } \\
\text { Ambient Air } \\
(\%)\end{array}$ & $\begin{array}{c}\text { Sensible Heat } \\
\text { Exchange } \\
(\mathbf{W})\end{array}$ & $\begin{array}{c}\text { Latent Heat } \\
\text { Exchange } \\
(\mathbf{W})\end{array}$ & $\begin{array}{c}\text { Total Heat } \\
\text { Exchange } \\
(\mathbf{W})\end{array}$ \\
\hline 0.947 & $34.9 \pm 0.8^{\mathrm{a}}$ & $31.5 \pm 1.2^{\mathrm{a}}$ & $73.9 \pm 2.2^{\mathrm{a}}$ & $54.3^{\mathrm{a}}$ & $415.6^{\mathrm{a}}$ & $469.9^{\mathrm{a}}$ \\
1.127 & $34.3 \pm 0.5^{\mathrm{b}}$ & $31.2 \pm 1.5^{\mathrm{b}}$ & $74.4 \pm 3.7^{\mathrm{b}}$ & $49.5^{\mathrm{a}}$ & $380.9^{\mathrm{a}}$ & $430.4^{\mathrm{a}}$ \\
\hline
\end{tabular}

Note: $(\mathrm{P}<0.05$, The different letters in the table indicate significant differences at $\mathrm{P}<0.05$ levels at different spray particle sizes.).

\section{Summary and Conclusions}

The current research results show that spray cooling can well alleviate heat stress in dairy cows, and this method is widely used in dairy farming production. However, this method also increases the generation of sewage in dairy farming. But, the results of previous studies did not clearly indicate the appropriate ADSD of the spray cooling. In this paper, 18 kinds of spray ADSDs were analyzed in the laboratory using simulated dairy cows and LPM tests. Based on the enthalpy difference theory, the range of spray ADSD was analyzed under three different environmental conditions to achieve better heat exchange effect, which provided a theoretical basis for field experiments. In the field test, the ITI is used to test the surface temperature of the dairy cow. The respiratory rate and rectal temperature of the dairy cow were tested in field experiments and the amount of heat exchange between the dairy cow and the surrounding environment was calculated. The ADSD suitable for the spray cooling of the cows was clarified, which saved on water consumption while alleviating the heat stress of the cows. The following conclusions were drawn.

- The laboratory experiment results showed that the ADSD range was from 0.475 to $1.21 \mathrm{~mm}$ at 0.1 , 0.15 , and $0.2 \mathrm{MPa}$ working pressure through the LPM test. Using the simulated cows through the theory of enthalpy differences formula, the ADSD range with good heat exchange effect was $0.914-0.995 \mathrm{~mm}$. The corresponding nozzles size were the 9080 and 90100 , which were suitable for field experiment spray cooling. 
- According to the laboratory test results, the corresponding two nozzles $(9080,90100)$ were used for field tests. At $0.1 \mathrm{MPa}$ working pressure, the ADSD corresponding to the nozzles were 0.947 and $1.127 \mathrm{~mm}$. The results showed that: In the condition of ADSD of $0.947 \mathrm{~mm}$, the decrease of respiratory rate and the increase of heat transfer volume were more obvious than those in the ADSD of $1.127 \mathrm{~mm}$. The water consumption in ADSD of $0.947 \mathrm{~mm}$ was $22.86 \%$ lower than that of ADSD of $1.127 \mathrm{~mm}$.

Author Contributions: Data curation, B.S.; writing—review and editing, T.D.; funding acquisition, Z.S. and B.L.

Funding: This study was funded by the National Fund of Natural Science of China (31402115), the National key research and development plan special project (2018YFF0213604) and the China Agricultural Research System (CARS-36).

Conflicts of Interest: The authors declare no conflict of interest.

\section{References}

1. Chen, F.Y.; Gao, Y.X.; Li, J.G. The risk of heat stress in dairy cows and its nutritional regulation. Chin. J. Anim. Sci. 2012, 48, 37-41.

2. West, J.W.; Mullinix, B.G.; Bernard, J.K. Effects of hot, humid weather on milk temperature, dry matter intake, and milk yield of lactating dairy cows. J. Dairy Sci. 2003, 86, 232-242. [CrossRef]

3. Flamenbaum, I.; Wolfenson, D.; Mamen, M.; Berman, A. Cooling dairy cattle by a combination of sprinkling and forced ventilation and its implementation in the shelter system. J. Dairy Sci. 1986, 69, 3140-3147. [CrossRef]

4. Igono, M.O.; Johnson, H.D.; Steevens, B.J.; Krause, G.F.; Shanklin, M.D. Physiological, productive, and economic benefits of shade, spray and fan system versus shade for Holstein cows during summer heat. J. Dairy Sci. 1987, 70, 1067-1079. [CrossRef]

5. Turner, L.W.; Chastain, J.P.; Hemken, R.W.; Gates, R.S.; Crist, W.L. Reducing heat stress in dairy cows through sprinkler and fan cooling. Appl. Eng. Agric. 1992, 8, 251-256. [CrossRef]

6. Zhang, F.J.; Guan, W.Y.; Yue, Y.; Yue, Y.; Hou, Y.X.; Wang, J.F. Taking physical cooling measures to protect dairy cows from heat stress. China Anim. Husb. Vet. Med. 2012, 39, 236-239.

7. Ma, C.W.; Huang, Z.D.; Li, B.M.; Cui, Y.A. The development of evaporative cooling technology or farm buildings. Trans. Chin. Soc. Agric. Eng. 1995, 11, 95-100.

8. Zhang, J.F.; Wu, J.; Mao, T.T.; Shi, Z.X. Optimization of spray scheme for spray cooling system of open cow house. China Dairy Cattle 2014, 22, 34-37.

9. Liu, J.A.; Ding, T.; Shi, Z.X.; Jia, C.T.; Li, H. The Study of Combined Irrigation of Dairy Spray Cooling System in Summer. In Proceedings of the Seminar on Sustainable Development of Ecological Environment and Animal Husbandry and Chinese Institute of Animal Husbandry and Veterinary Medicine Conference in 2012 and the Seventh National Animal Husbandry and Veterinary Science and Technology Workers Youth Symposium on T01 in the Barn Environment and Control Technology, Beijing, China, 2-5 November 2012; pp. 205-212.

10. Ding, T.; Li, H.; He, X.D.; Bian, L.H.; Li, X.W. Optimization of nozzle in spray cooling system in summer dairy farm. Chin. J. Anim. Sci. 2012, 45, 33-37.

11. Ding, T.; Hong, S.; Shi, Z.X.; Fang, L.M.; Sun, B.X.; Zhang, C.Y. Experiment on droplet characteristics of spray cooling to relieve cows heat stress. Trans. Chin. Soc. Agric. Mach. 2016, 7, 323-331.

12. Li, H. Optimization and Evaluation of Cooling Effectiveness on Spray Cooling System in Open Dairy Barns; China Agricultural University: Beijing, China, 2013.

13. Cai, J.Y.; Feng, T.C.; Liao, K.Y.; Du, Z.F.; Yi, Z.R. Cooling with fans and spray in closed cowshed and chromium supplementation improving growth performance of beef cattle. Trans. Chin. Soc. Agric. Eng. 2015, 31, 190-194.

14. Liu, H.L.; Gao, S.; Duan, H.F.; Zhang, B.Z. Study on the effect of spray cooling on heat-stress resistance of Holstein dairy cow. Acta Ecol. Anim. Domastici 2013, 1, 44-59.

15. Gebremedhin, K.G.; Wu, B.X. A model of evaporative cooling of wet skin surface and fur layer. J. Therm. Biol. 2001, 26, 537-545. [CrossRef] 
16. Gebremedhin, K.G.; Wu, B.X. Simulation of sensible and latent heat losses from wet-skin surface and fur layer. J. Therm. Biol. 2002, 27, 291-297. [CrossRef]

17. Khan, Z.A.; Badruddin, I.A.; Quadir, G.A.; Seetharamu, K.N. A quick and accurate estimation of heat losses from a cow. Biosyst. Eng. 2006, 93, 313-323. [CrossRef]

18. Duan, X.R. Performance Analysis and Diagnosis of a Fooling Tower in an Air-Conditioning System; Hunan University: Changsha, China, 2011.

19. Hong, S. Research on Droplet Characteristics of Spray Cooling to Relieve Heat-Stress of Cow in Summer; China Agriculture University: Beijing, China, 2016.

20. An, X. A Study of Partial Cooling Effect Based on the Heat Sensitive Body Surface of Dairy Cows; China Agriculture University: Beijing, China, 2018.

(C) 2019 by the authors. Licensee MDPI, Basel, Switzerland. This article is an open access article distributed under the terms and conditions of the Creative Commons Attribution (CC BY) license (http://creativecommons.org/licenses/by/4.0/). 